me engaged several hours, so that I did not return to my first patient until full eight hours after having left her. On my arrival, I found things much in the same position, except more fatigue and disinclination on her part to have any remedy tried. I now decided on bleeding her freely, which I had hesitated to do previously, from the apparent great exhaustion and the consideration that I might hasten gangrene by weakening the powers of life; I accordingly opened a vein in the arm, and when about twelve ounces had flown, perfect syncope occurred; I heard a slight gurgling, and with gentle taxis the whole contents of the sac were returned into the cavity of the abdomen. A full dose of castor oil was given as soon as the state of collapse succeeding had been removed by slight stimuli; this being rejected, I administered other aperients, which moved the bowels in about four or five hours, and she went on well from this time with scarcely any symptoms requiring treatment.

The only point of interest perhaps in this case may be the long period of incarceration of the contents of the sac (nearly seven days), together with the absence of adhesions, which would have been expected from the continued inflammation, and its publication may serve to illustrate the difficulty surgeons sometimes have in deciding on the exact time of giving up measures for reducing strangulated hernia, and having immediate recourse to an operation. It is now well understood that the earlier we operate the better, but the above detail may serve to show to what a period such symptoms may go on without the death of the patient. Had any medical friend accompanied me on my first attendance, I shquld have been inclined to operate at once, being satisfied that no delay should ever occur in relieving symptoms so urgent, and when other remedies fail, harm is done by the loss of time. Baron Larrey mentions a case in which death occurred in two hours from the strangulation; and Mr. Hey two cases where the disease proved fatal in about twenty-four hours. In this case the usual symptoms which point out its immediate necessity were present, but the unintentional delay most probably saved the patient a painful and dangerous operation, which, under the circumstances, held out few prospects of recovery.

It may seem strange to some of your readers the long delay in my being called into the patient, which may be explained by the circumstance of her living with a bedridden sister between two or three miles from my residence, and the neighbours being ignorant of and indifferent to her state.

\section{DIAGNOSIS OF CHOLERA.}

\section{TO THE EDITORS OF THE PROVINCIAL MEDICAL} JOURNAL.

Gentlbmen,-In conformity with the intention expressed in my letter of the lst inst., I now proceed to a more detailed account of some of the statements therein contained. In doing this, I will deviate so far from the ordinary course pursued in medical writings as to reserve till the last what $I$ have to add on the origin or causation of the disease; my reason for so doing being the conviction that, in a disease so anomalous, it is not only legitimate to disregard established usage, but further, when the more peculiar features have been duly discussed, much irrelevant and tedious reretition will be avoided. Feeling persuaded that enough has already been said to prove the "irreconcilable" difference between English cholera and the Asiatic or malignant disease, I shall pass at once to the examination of the first statement, which appears to call for comment-viz., "diarrhœa and vomiting may, or may not, be present."

My object in pointedly making the above assertion was to convey the idea that, although of almost universal occurrence at one or other period of the disease, diarrhœa and vomiting do not act the part in the production of collapse generally assigned to them; and also to lead to the more important conclusion, that the practitioner who rests satisfied with arresting them has performed but a portion of his duty. To this it will be necessary to revert when considering the treatment. In confirmation of the foregoing statement, I have at this moment in my recollection three cases, wherein the patients were in the state of collapse within an hour of the first feeling of indisposition, and where neither diarrhœa nor vomiting had preceded such condition, although these symptoms in their least equivocal form supervened. Again, if we regard the character of the matter discharged, of what do we find it to consist? Certainly not of the matters usually met with in English cholera, or dysentery, but, on the contrary, of the soluble parts of the blood blended with the secretion proper to the intestinal canal, in a state of partial solution and partial coagulation, to the presence of which (mucus) the term rice-water has been not inaptly given. That the immense discharges are, in reality, derived from the source above mentioned will be self-evident, when we arrive at the consideration of the state of the circulation, whether we regard the condition of the blood met with in the vessels, or that abstracted from the body during life. There is yet another peculiarity connected with the diarrhœa, which is the immense force with which the discharge is effected, and which seems to depend on the violent or spasmodic contraction of the muscular apparatus of the intestines, and the total inability of the sphincter to counteract it. This must have been observed by every man who has had the opportunity of seeing the disease, and, in confirmation of its truth, I would particularly advert to my own case. The same remark to a certain extent applies to the vomiting.

I shall now notice the suppression of the secretions of the liver and kidneys, not that this may be next in importance, but because it is more immediately connected with the natural functions, and forms a most prominent diagnostic feature in the disease. That this symptom is to be regarded in the light mentioned does not admit of question, as every man who has practical knowledge of the disease can testify. It only, therefore, is necessary for me to explain a little more fully a remark already made-viz, that this suppression of the secretions of two such important organs is universally present, and that it arises from their inability "to act upon the morbid fluid circulating through them." That this suppression is actually what its name implies, has been most abundantly proved by post-mortem investigations, the almost invariable result of which has been the totally empty and collapsed state both of the gall and urinary bladders. To this there is, however, ane 
cxception, and this should not be passed over-viz., where such examinations have been made after reaction had taken place, and where that most fatal of all causes, cerebral congestion with consecutive fever, proved the cause of death, and where, in fact, a new disease had occurred. That the blood circulating through the liver and kidneys is altered in constitution physically and chemically, camnot be denied, and is, therefore, unfit for the purposes to which, in its healthy state, it is destined, may be safely inferred. That this explanation might in itself suffice to prove the assertion made, seems apparent ; but another fact, and one of paramount weight, may be added-it is, that these organs which suffer in common with all others dependent on the ganglionic system of nerves for their integrity and power of action, are still further incapacitated for the discharge of their parts in the economy by the abstraction or subversion of such nervous influence. This will be further illustrated when we arrive at the consideration of the derangement of the nervous system.

The next point which claims attention is the extraordinary diminution of the heat of the body. This is deserving of remark on many accounts, and not least so as going far to destroy the idea of cholera being the consequence of an irritative or inflammatory state of the system. It is also to be remembered that this coldness is not confined to the surface of the body, but is even more remarkable on touching the tongue, which, so far as my experience extends, is universally cold and clammy. That this symptom depends upon some cause more immediately connected with the laws by which the generation and evolution of animal heat are governed, can hardly be a matter of doubt. Although how or in what manner such derangement is produced is involved in the greatest obscurity, and must so remain until the subject of animal heat is better understood than at present. Conceiving that nothing acts so prejudicially to the real advancement of medical science as the indulgence in hypothesis, 1 shall not stop to inquire into the doctrines at present entertained on this subject by either one or other party, but will rest satisfied with stating my belief that this symptom, in common with others, may be fairly attributed to the defective and disordered state of the nervous, the respiratory, and circulatory systems-on the due performance of which functions I also believe the generation of animal heat itself to be mainly dependent. If this opinion be erroneous, and the production of animal heat be referrable to mere physical and chemical agency, independent of vital or nervous influence, why does not this extraordinary process continue after dissolution, when such causes are no longer interfered with, or interrupted by that principle which, during life, seems to keep them in abeyance?

The next point requiring attention is the state of the respiration. As stated in my first letter, we find it slow, feeble, and the air expired cold; the parietes of the chest scarcely moving; and, so far as my observation enables me to speak, such disordered state never accompanied by stertor. I here confess with regret that I never, during the prevalence of the disease, endeavoured to ascertain the quantity of carbonic acid emitted on expiration. This condition of the respiration I have noticed in many of the more aggravated cases from the very commencement of the disease, which confirms me in the opinion already expressed -viz., that the blood, owing to such impaired action of the lungs, does not undergo the change in them by which it is rendered fit for the purposes of life; or, in other words, from the partial expulsion of the contaminated air in these organs, the ingress of a due proportion of fresh atmospheric air is effectually prevented; and, hence, instead of oxygenated or arterialised blood, we have a literally poisonous fluid circulating through every organ of the body, as is most abundantly demonstrated by the dark and tarry appearance of the blood, more especially of the portions first drawn by venesection, and, where this means is practised with success, the gradual improvement in appearance of that which flows subsequently. Of this it will be necessary to speak when considcring the state of the circulating and nervous systems, which I shall take the earliest opportunity of doing, as by such extension of the remarks contained in my former letter, I hope to succeed in divesting them of the character of mere assertion.

I am, Gentlemen,

Your obedient Servant, George Fyfe.

Newcastle-upon-Tyne, Dec. 26, 1842.

\section{INFLUENCE OF MENTAL IMPRESSIONS ON} 'THE FOETUS IN U'TERO.

TO THE EDITORS OF THE PROVINCIAL MEDICAL JOURNAI.

Gentlemen,-For the facts of the following case, which has recently occurred in my practice, I can vouch; though how far they may tend to support the opinion long controverted, but adopted by many, that the effects of maternal fright may be developed in the organisation of the fotus in utero, I must leave to your numerous readers to decide.

I am, Gentlemen,

Your obedient servant, W. J. TubBs.

Upwell, Norfolk, December 21, 1812.

In the early part of August, 1841, I was requested to attend the wife of an innkeeper, in labor with her eighth child. She was a strong, healthy woman, aged about forty-seven. The os uteri was dilated to the size of half a crown; membranes unruptured; vertex presentation. The labor being tedious, it was necessary to rupture the membranes, which, from their toughness, and not yielding to the finger nail, was effected by a quill. There was much mental excitement during the greater part of the labor. Fearing cerebral congestion, and from the rigid state of the os uteri and the perineum, it was almost decided that venesection should be had recourse to. Though repeatedly told all was right, she persisted in a contrary opinion. As her pains increased, so did her ideas, that her child was like the spotted dog by which she had been frightened in the kitchen; as it was always before her eyes, night and day. (These were the words of the patient.) She had scarcely uttered those words, when, by a powerful contraction of the uterus, a fine full-grown female child was expelled. 